\title{
Promoção da saúde do jovem agricultor familiar: perspectiva para um envelhecimento saudável
}

Health promotion for young family farmers: perspective for healthy aging

Promoción de la salud de los jóvenes agricultores familiares: perspectiva para un envejecimiento saludable

\section{Ângela UrioI ${ }^{\mathrm{I}}$ Jeane Barros de Souza"I, Daniela Savi Geremia' ${ }^{\mathrm{III}}$, Ivonete Teresinha S. Buss Heidemann $^{\mathrm{IV}}$, Liane Colliselli ${ }^{\mathrm{V}}$}

\begin{abstract}
Resumo: Objetivo: compreender como jovens agricultores cuidam da saúde, diante das vulnerabilidades no contexto de trabalho, desvelando suas perspectivas para o envelhecimento saudável. Método: pesquisa exploratória, descritiva, qualitativa, realizada com dez jovens de um município do Rio Grande do Sul, realizada no segundo semestre de 2018. A coleta dos dados ocorreu por meio de entrevistas semiestruturadas. A análise dos dados foi baseada na análise de conteúdo. Resultados: os jovens promovem sua saúde cuidando da alimentação, ingestão hídrica, adaptações climáticas, lazer e manutenção das relações familiares. Para o envelhecimento saudável, os participantes da pesquisa buscam inserção de tecnologias para aliviar esforço físico e adesão de práticas preventivas, demonstrando preocupações hereditárias e de comorbidades. Conclusão: a promoção da saúde é realizada a partir dos cuidados com a alimentação, ingesta hídrica, adaptações ao clima e das boas relações familiares. Os exercícios físicos não são praticados devido às atividades laborais demandarem intenso esforço físico.
\end{abstract}

Descritores: Promoção da saúde; Adulto jovem; População rural; Saúde do trabalhador

Abstract: Objective: to understand how young farmers take care of their health in the face of vulnerabilities in the work context, thereby unveiling their perspectives for a healthy aging. Method: exploratory, descriptive and qualitative research, performed with ten young people from a town in Rio Grande do Sul, held in the second half of 2018. Data collection took place through semi-structured interviews. Data analysis was based on content analysis. Results: young people promote their health by taking care of food, water intake, climatic adaptations, leisure and maintenance of family

\footnotetext{
${ }^{\text {I }}$ Enfermeira, Residente em Obstetrícia. Universidade Federal da Grande Dourados. Dourados, MS, Brasil. E-mail: ange.urio@hotmail.com ORCID: http://orcid.org/0000-0001-5851-4168.

${ }^{I I}$ Enfermeira, Doutora em Ciências da Saúde. Universidade Federal da Fronteira Sul. Chapecó, SC, Brasil. E-mail: jeanebarros18@gmail.com ORCID: http://orcid.org/0000-0002-0512-9765.

III Enfermeira, Doutora em Saúde Coletiva. Universidade Federal da Fronteira Sul. Chapecó, SC, Brasil. E-mail: daniela.savi.geremia@gmail.com ORCID: http://orcid.org/0000-0003-2259-7429.

IV Enfermeira, Ph.D. Professora do Departamento de Enfermagem da Universidade Federal de Santa Catarina. Florianópolis, SC, Brasil. E-mail: ivoneteheideman@gmail.com.br. ORCID: http://orcid.org/0000-0001-6216-1633.

${ }^{v}$ Enfermeira, Mestre em Enfermagem. Universidade Federal da Fronteira Sul. Chapecó, SC, Brasil. E-mail: liane.colliselli@uffs.edu.br ORCID: http://orcid.org/0000-0002-2774-5083.
} 
relationships. For healthy aging, research participants seek the introduction of technologies focused on relieving physical effort and adhering to preventive practices, showing hereditary concerns and comorbidities. Conclusion: health promotion is held from the care with food, water intake, adaptations to the climate and good family relationships. Physical exercises are not practiced because work activities require intense physical effort.

Descriptors: Health promotion; Young adult; Rural population; Worker's health

Resumen: Objetivo: comprender cómo los jóvenes agricultores cuidan su salud ante las vulnerabilidades en el contexto laboral, desvelando sus perspectivas para un envejecimiento saludable. Método: investigación exploratoria, descriptiva y cualitativa, realizada con diez jóvenes de un ayuntamiento de Rio Grande do Sul, conducida en el segundo semestre de 2018. La recolección de datos tuvo lugar mediante entrevistas semiestructuradas. El análisis de datos se basó en el análisis de contenido. Resultados: los jóvenes promueven su salud al cuidar los alimentos, la ingesta hídrica, las adaptaciones climáticas, el ocio y el mantenimiento de las relaciones familiares. Para un envejecimiento saludable, los participantes de la investigación buscan la introducción de tecnologías para aliviar el esfuerzo físico y la adherencia a las prácticas preventivas, demostrando preocupaciones hereditarias y comorbilidades. Conclusión: la promoción de la salud se realiza basándose en la atención con alimentos, ingesta hídrica, adaptaciones al clima y buenas relaciones familiares. Los ejercicios físicos no se practican porque las actividades laborales requieren un esfuerzo físico vigoroso.

Descriptores: Promoción de la salud; Adulto joven; Población rural; Salud del trabajador

\section{Introdução}

A atividade agrícola pode se constituir em um trabalho perigoso à medida que são observados alguns riscos que os trabalhadores estão expostos, tais como: o uso de máquinas, o contato com plantas e animais em ambientes internos e externos, a exposição a variações climáticas e a produtos químicos. ${ }^{1}$ A extensiva utilização dos agrotóxicos vem representando um problema de saúde pública em países subdesenvolvidos, especialmente para aqueles que possuem a economia voltada ao agronegócio, a exemplo do Brasil. ${ }^{2}$

A exposição do trabalhador rural aos herbicidas, inseticidas, fungicidas, bactericidas, acaricidas e fertilizantes por meio direto, compreendido como não uso ou o uso inadequado dos Equipamentos de Proteção Individual (EPIs), pode levar à intoxicação aguda ou crônica. ${ }^{1}$ Sob tais circunstâncias, o produtor rural é diretamente afetado pelos efeitos das substâncias químicas. Desse modo, ele precisa ser o primeiro a tomar providências quanto a promoção da sua saúde. O ramo da agricultura depende da adoção de práticas que conservem o meio ambiente e a condição de saúde. ${ }^{3}$ 
3 | Urio A, SouzaJB, Geremia DS, Heidemann ITSB, Colliselli L

A Política Nacional de Saúde das Populações do campo, das florestas e das águas, lançada em 2011 e revisada em 2013, tem como objetivo melhorar o nível de saúde das populações às quais se destina. A política almeja facilitar o acesso aos serviços de saúde, promover a redução de riscos decorrentes dos processos de trabalho e das inovações tecnológicas agrícolas, e melhorar a qualidade de vida daquelas populações.

Tal política define ações estratégicas determinadas pelo documento, a saber: acesso aos serviços de saúde; promoção e vigilância em saúde; educação permanente e educação popular em saúde; monitoramento e avaliação do acesso às ações e serviços de saúde. As ações buscam atuar sobre os determinantes e condicionantes de saúde das populações. ${ }^{4}$

A dinâmica de vida dos jovens trabalhadores de áreas rurais envolve, no entanto, situações peculiares que deveriam ser atendidas e levadas em consideração na organização da atenção à saúde. ${ }^{5}$ Os jovens, por serem considerados saudáveis, geralmente não têm a necessária atenção à saúde, a não ser nas questões de saúde reprodutiva. Sendo assim, as condições de saúde desse grupo tornaram-se um diferencial que evidencia a vulnerabilidade desses jovens frente às diferentes formas de violências e a crescente incidência de mortalidade, demonstrando que decorrem especialmente de causas externas. ${ }^{6}$

Extrapolando a noção de risco, compreende-se por vulnerabilidade a multideterminação de sua concepção não estritamente condicionada à falta de acesso a renda, mas também às fragilidades de laços relacionais e desigualdade de acesso a bens e serviços públicos. ${ }^{7}$

O fato é que os jovens agricultores, por vezes, ficam desassistidos no âmbito da saúde pela preconcepção de que são saudáveis. Com isso, as consequências surgem de forma silenciosa, uma vez que tendem a não utilizarem corretamente os EPIs, o que contribui para a não promoção da saúde na contemporaneidade, e sem refletir nas consequências para o futuro desta geração de jovens agricultores. 
Promoção da saúde do jovem agricultor familiar: perspectiva para um envelhecimento... $\mid 4$

De acordo com a legislação brasileira, uma pessoa com idade entre 15 e 29 anos é considerada jovem. ${ }^{8}$ No entanto, um jovem adulto também pode ser descrito como sendo aquele acima de 18 anos. $^{9}$ Para este estudo, considerou-se jovem aquele que possui idade entre 18 e 29 anos.

Nessa perspectiva, emergiram os seguintes questionamentos: como os jovens agricultores cuidam da saúde diante das vulnerabilidades que vivenciam na rotina de trabalho? Quais as perspectivas desses indivíduos para o envelhecimento saudável?

Assim, tem-se por objetivo, neste estudo, compreender como os jovens agricultores cuidam da sua saúde, diante das vulnerabilidades no contexto de trabalho, desvelando suas perspectivas para o envelhecimento saudável.

\section{Método}

Trata-se de um estudo do tipo exploratório, descritivo, com abordagem qualitativa. A pesquisa teve como cenário um município localizado no noroeste do Estado do Rio Grande do Sul. O município tem cerca de 4.830 habilitantes e possui 2.435 propriedades rurais.

Participaram do estudo 10 jovens agricultores, os quais foram contatados e identificados com o auxílio do Sindicato de Trabalhadores Rurais do município. Como critérios de inclusão na pesquisa, foram considerados somente os jovens que possuíam notas fiscais de produtor rural. Como critérios de exclusão, foram desconsiderados os jovens que não estivessem exercendo a profissão de agricultor familiar naquele momento.

A coleta de dados ocorreu no segundo semestre do ano de 2018, e foi realizada por meio de entrevista com cada participante. Tais entrevistas tiveram duração média de uma hora e seguiram um roteiro contendo questões semiestruturadas sobre seu perfil sociodemográfico. Os itens contemplados foram: idade; cor/raça; escolaridade; religião; ramo de atuação da agricultura 
5 | Urio A, SouzaJB, Geremia DS, Heidemann ITSB, Colliselli L

familiar; quanto tempo está atuando e motivo de atuar na agricultura familiar; com quem reside; estado civil; filhos; atuação em outra profissão; os riscos ocupacionais expostos; os cuidados tomados perante os riscos; e sobre a promoção da saúde.

As entrevistas foram realizadas nas residências dos participantes, em um momento previamente agendado. A definição do lugar e momento de realização da entrevista visa a garantia de um diálogo sem interrupções. O início das entrevistas ocorreu após a assinatura do Termo de Consentimento Livre e Esclarecido, respeitando o sigilo e anonimato.

Foi realizada a análise de conteúdo a partir dos dados coletados. ${ }^{10}$ Para tanto, após a organização dos dados, realizou-se a exploração do material de análise, com a organização da codificação, escolha das unidades, das regras de contagem e, por fim, a definição de duas categorias, que assim ficaram definidas: Promoção da Saúde e Perspectivas com a saúde: como será o envelhecimento?

Esta pesquisa teve início após a aprovação do projeto pelo Comitê de Ética em Pesquisa da Universidade Federal da Fronteira Sul, campus Chapecó-SC, o qual tem como Certificado de Aprovação para Apreciação Ética (CAAE) no .88518418 .1 .0000 .5564 , datado de 05 de junho de 2018. Como forma de manter o anonimato dos participantes, em consonância com a Resolução n466/2012, foram utilizados codinomes de frutas produzidas no município em estudo, representando uma das produtividades da agricultura familiar.

\section{Resultados e discussões}

A pesquisa desenvolveu-se com 10 jovens agricultores familiares na faixa etária de 21 a 28 anos, sendo oito do sexo masculino (80\%) e dois do sexo feminino (20\%), católicos (100\%), de cor/raça branca (100\%), oito solteiros (80\%) e dois casados com filhos (20\%). Seis dos participantes $(60 \%)$ possuíam o ensino médio completo e quatro $(40 \%)$ o ensino fundamental 
Promoção da saúde do jovem agricultor familiar: perspectiva para um envelhecimento... | 6

completo. Os entrevistados atuavam, em sua maioria, na produção de leite (60\%), como também de hortifrútis/frutas (20\%), suínos/bovinos (10\%) e na agroindústria (10\%).

O tempo de atuação na área variou desde a infância até 3 anos anteriores à entrevista. Os motivos de trabalhar na agricultura foram: gosto pela atividade realizada; atuação da família no ramo; qualidade de vida; e autonomia em realizar as ações no trabalho. Dois jovens (20\%) já tiveram outros vínculos empregatícios como comerciante e empregada doméstica. Os demais nunca atuaram em outras áreas, seja pela falta de interesse, por gostar das atividades que são desenvolvidas na agricultura, ou ainda por desejar dar continuidade ao que a família já vinha realizando.

\section{Promoção da Saúde}

A Conferência Internacional sobre Promoção da Saúde, realizada em Ottawa, no Canadá, em 1986, estabeleceu uma série de princípios éticos e políticos. Esses definiram os campos de ação e o conceito de promoção da saúde como o processo de capacitação da comunidade para atuar na melhoria da sua qualidade de vida e saúde, o que a inclui no controle desse processo. ${ }^{11}$

Em 2006, o Ministério da Saúde criou a Política Nacional de Promoção da Saúde com o objetivo de promover a qualidade de vida e reduzir vulnerabilidade e riscos à saúde relacionados aos seus determinantes. Nesta política, são feitas menções a condições de trabalho, moradia, meio ambiente, educação, lazer, cultura e acesso a bens e serviços essenciais. ${ }^{12}$ Mas, para atingir um estado de completo bem-estar físico, mental e social, os indivíduos e grupos devem saber identificar aspirações, satisfazer necessidades e modificar favoravelmente o ambiente natural, político e social. ${ }^{11}$ A saúde é, portanto, um conceito positivo, que enfatiza os recursos sociais e pessoais, bem como as capacidades físicas.

Como se sabe, a alimentação saudável é um dos pilares da promoção da saúde,${ }^{6}$ e emergiu no relato de alguns dos participantes deste estudo, os quais afirmam que: 
7 | Urio A, SouzaJB, Geremia DS, Heidemann ITSB, Colliselli L

Principalmente na alimentação, consumir bastante frutas, verduras e aqui conseguimos consumir tudo fresco, tudo o que produzimos [...]. (Uva)

[...] A alimentação, a gente tenta produzir tudo na horta de casa [...]. (Pêssego)

As políticas públicas, a partir dos anos de 1980, passaram a seguir as recomendações da Food and Agriculture Organization (FAO) e da World Health Organization (WHO), que propunham melhorar ou ampliar a qualidade de vida das pessoas. Tais proposições visam contribuir com as populações de modo que tenham capacidade de viver independentemente das instituições, tendo ainda habilidades financeiras e físicas para escolherem com responsabilidade suas próprias refeições e alimentos. ${ }^{13}$

Além da alimentação saudável, para promover a saúde, a ingesta hídrica é importante na realização de um trabalho físico. Caso haja perda líquida maior do que a ingestão, o agricultor poderá sofrer desidratação, e ter a produtividade, segurança e saúde significativamente afetadas, ${ }^{14}$ como evidenciado nesta pesquisa.

[...] Também cuido sempre a questão da água, porque a gente sua bastante com o calor, e tem que hidratar o corpo [...]. (Ameixa)

As mudanças climáticas também interferem diretamente na saúde do agricultor, ${ }^{2}$ e esse fator foi evidenciado pelos jovens agricultores.

[...] quando chove que é o ruim, frio, tem que se cuidar mais [...]. (Laranja)

[...] Proteção do sol também, tenho usado protetor. (Maracujá)

Os relatos retratam os agentes físicos nocivos à saúde, referindo à exposição a temperaturas extremas. A exposição à chuva e ao frio implica no risco de desenvolver resfriados, gripes, sinusites e bronquites. Portanto, para evitar possíveis doenças, é relevante a utilização de capas de chuvas, botas de borracha e roupas que protejam o trabalhador do frio. ${ }^{15}$ 
Promoção da saúde do jovem agricultor familiar: perspectiva para um envelhecimento... $\mid 8$

A não proteção ao sol também é um aspecto relevante, uma vez que além de oferecer riscos de câimbras, fadiga, desmaios, insolação, potencializa o risco de desenvolver câncer de pele. Essas condições têm implicações diretas na saúde dos trabalhadores, e reforçam a necessidade da utilização de protetor solar, chapéus e roupas que protejam o corpo. ${ }^{15}$

Outro ponto destacado, como maneira de promover a saúde, foi manter a relação familiar.

Você tem que ter uma boa convivência na família [...] os trabalhadores da agroindústria, são da família, precisa ter uma convivência senão fica um ambiente estressante, ruim de trabalhar. (Figo)

A família é um conjunto de pessoas consideradas como unidade social, um todo sistêmico, e é marcada pelas relações entre os membros que a compõem e o meio exterior. A instituição família desempenha funções importantes na sociedade, como o afeto, a educação, a socialização. Pode ser considerada um sistema comunicacional que contribui para a construção de soluções integradoras dos seus membros.

É da família a responsabilidade de promover o desenvolvimento completo e harmonioso da personalidade de cada indivíduo num ambiente de felicidade, amor e compreensão. A construção de um contexto com essas características influenciará na saúde dos respectivos membros, do contrário, pode se tornar um ambiente estressor. ${ }^{16}$

A falta de atividade física é considerada um dos problemas significativos de saúde pública no século XXI. Além de representar um componente importante para um estilo de vida saudável e para promoção da saúde, a prática de exercícios atua na prevenção de doenças crônicas não transmissíveis. A inatividade física ocupa a quarta posição entre principais fatores de risco para mortalidade global, suplantada pela hipertensão, tabagismo e glicemia elevada. ${ }^{17}$ Os jovens agricultores familiares relataram, no entanto, que não realizam exercícios físicos por considerarem que já exercem diversas atividades no trabalho rural. 
9 | Urio A, SouzaJB, Geremia DS, Heidemann ITSB, Colliselli L

Exercício físico muito pouco, tipo a gente faz caminhada, mas porque tem que fazer no trabalho, mas parar um tempo para fazer exercícios, não. (Amora)

[...] exercício físico é o trabalho de todos os dias. Mais ou menos se fosse comparar com a cidade, a academia aqui é direto [...]. (Ameixa)

O trabalho no ambiente rural envolve atividades físicas como caminhadas frequentes, transportes de materiais e produtos. O exercício físico é, no entanto, aquela prática planejada e estruturada que tem por finalidade melhorar os componentes do condicionamento físico, tais como o equilíbrio, a flexibilidade, força, coordenação, agilidade, resistência muscular e cardiorrespiratória. ${ }^{17}$

Os exercícios físicos podem ser compreendidos como ações mais simples, como caminhadas, por exemplo. Para manter-se ativo, há que se manter boa flexibilidade, componente essencial da aptidão física que, associada a níveis adequados de força, melhora a eficiência do movimento e reduz a incidência de distensão muscular. Este aspecto é fundamental para evitar quadros álgicos, comuns aos trabalhadores rurais. ${ }^{17-18}$

Neste estudo, evidenciou-se que nem sempre a promoção da saúde é realizada pelos jovens agricultores familiares, pois alguns afirmaram que não conseguem tempo para se cuidar.

A gente não tira um tempo para fazer 15 minutos de exercício para fortalecer a coluna, a musculatura, a gente não para, não tem esse cuidado com a gente mesmo. (Amora)

O trabalho na agricultura envolve tanto atividades físicas, quanto o contato direto com agentes químicos, físicos e biológicos de diferentes naturezas. Assim, o desenvolvimento de agravos à saúde, tais como dores lombares e a perda da flexibilidade, podem estar associados à sobrecarga de atividades relacionadas ao trabalho e à falta de atividades preventivas ou compensatórias. ${ }^{17}$

Fica evidente, no relato de Amora, a falta do autocuidado, que é uma função reguladora que permite às pessoas desempenharem as atividades que visam a preservação da vida, da saúde, 
Promoção da saúde do jovem agricultor familiar: perspectiva para um envelhecimento... | 10

do desenvolvimento e do bem-estar. Caberia, neste contexto, o incentivo às práticas de autocuidado para a população rural. ${ }^{19}$

A promoção da saúde consiste na compreensão conceitual e na prática de políticas públicas, e deve ter como foco tanto o indivíduo, quanto o coletivo. Isso é possível por meio da busca de qualidade de vida, da autonomia e do estímulo ao autocuidado, ${ }^{11}$ o que seria muito importante para a saúde dos jovens agricultores familiares.

Outros jovens agricultores familiares afirmaram ainda que não realizam medidas de promoção de saúde.

Acho que não muito, às vezes a gente na pressa, faz tudo de qualquer jeito, nem pensa na saúde [...]. (Pêssego)

Acho que não [...] pouco [...] nem se pensa em promover a saúde. (Lima)

A não realização de cuidados visando a promoção da saúde deve-se ao fato de se tratar de um público que necessita do envolvimento mais ativo do setor saúde. As demandas dos jovens não têm sido consideradas prioritárias pelo serviço de saúde, uma vez que a oferta de ações é condicionada à disponibilidade dos profissionais e/ou das equipes de saúde. Essa realidade faz com que a oferta seja assimétrica e não sistemática, com concepções, por vezes estereotipadas e fora da realidade da população. ${ }^{20}$

Visando a superação do quadro descrito, os enfermeiros deveriam buscar estratégias para promover a saúde do trabalhador rural com ações que sejam adequadas às necessidades de cada local, tenham sentido no viver dos jovens agricultores e, assim, sejam efetivas.

\section{Perspectivas com a saúde: como será o envelhecimento?}

A saúde é a primeira e mais importante forma de riqueza para a vida e deveria, por essa razão, ser construída no cotidiano, dentro das possibilidades e pelos próprios indivíduos. Por estar relacionada à qualidade de vida do jovem adulto, ela é alcançada por meio da satisfação 
11 | Urio A, SouzaJB, Geremia DS, Heidemann ITSB, Colliselli L

pessoal, do desenvolvimento de competências sociais e, também, da manutenção relativamente duradoura de comportamentos. ${ }^{21}$

Quando questionados sobre o envelhecimento, alguns jovens relataram que vislumbram a terceira idade de forma saudável.

Eu queria muito no futuro ter uma vida muito saudável, não precisar tomar muitos medicamentos. (Pêssego)

Eu espero que eu tenha saúde, mas hoje você vê que as pessoas com 50 e poucos anos estão com câncer, e morrendo. (Lima)

Para promover a saúde no presente, é preciso atingir o primeiro nível das medidas preventivas e de promoção da saúde, agindo antes da instalação da doença. A promoção da saúde é uma estratégia que chamam a atenção das pessoas para os fatores de risco e agravos à saúde. Deve direcionar a atenção para o atendimento do indivíduo, neste caso, do jovem agricultor familiar, e elaborar mecanismos que reduzam as situações de vulnerabilidade. ${ }^{11} \mathrm{Um}$ participante deste estudo relatou que na zona rural é possível ter uma melhor qualidade de vida, em comparação à vida urbana.

A gente pode produzir o que a gente consome e ter uma qualidade de vida melhor do que na cidade, comprando tudo do mercado, tudo industrializado, eu acho que é bem pior pra saúde da gente. (Uva)

O campo, para muitas pessoas, é qualificado como um local que promove qualidade de vida. Reverenciando o ambiente físico e social, a agricultura familiar surgiu como um novo paradigma coletivo integrador ao declarar como pressuposto a promoção do bem-estar e da qualidade de vida dos trabalhadores rurais. Neste cenário, esse modelo contrapõe-se ao empresário rural produtivista, tecnicista e predador (agricultura patronal). ${ }^{22}$

Mensurar qualidade de vida é uma tarefa complexa, pois seu conceito se relaciona a uma série de aspectos, como a autoestima e o bem-estar pessoal. A compreensão desses aspectos 
Promoção da saúde do jovem agricultor familiar: perspectiva para um envelhecimento... | 12

pode ser condicionada a fatores culturais e éticos, à religiosidade, ao estilo de vida, à satisfação com o emprego ou atividades diárias, ao ambiente em que se vive, entre outros. ${ }^{1}$

É importante destacar que o conceito ampliado de saúde é considerado como o resultado das condições de alimentação, habitação, educação, renda, meio ambiente, trabalho, transporte, emprego, lazer, liberdade, acesso e posse da terra e acesso aos serviços de saúde. ${ }^{12}$ Nessa perspectiva, a saúde é, principalmente, resultado das formas de organização social e de produção, podendo gerar desigualdades nos níveis de vida.

O lazer foi relatado pelos participantes deste estudo como forma de promover a saúde:

Jogo futebol nos finais de semana para dar risada, rever amigos, por lazer. (Pêssego)

[...] nos finais de semana a gente usa para se divertir, eu gosto de jogar futebol e ver amigos. (Figo)

As atividades de lazer se referem a uma área específica da experiência humana com seus próprios benefícios, incluindo liberdade de escolha, criatividade, satisfação, diversão e aumento de prazer e felicidade. Esse determinante da condição de saúde abrange formas amplas de expressão e de atividades, cujos elementos são tanto de natureza física quanto intelectual, social, artística ou espiritual. ${ }^{23}$

Para os jovens agricultores, a inserção de novas tecnologias para diminuir o esforço físico é também uma maneira de promover a saúde.

Temos que ir substituindo a mão de obra por máquinas [...] para ser menos desgastante para saúde [...] porque hoje na verdade já é comprovado que de tanto serviço repetitivo você já acaba tendo sérios danos. (Figo)

Considerando a limitada mecanização do setor, o trabalho agrícola em propriedades familiares caracteriza-se pelo elevado esforço físico, o que acarreta reflexos na saúde dos agricultores, e comprometem a produtividade. A ergonomia aplicada possui potencial para 
13 | Urio A, SouzaJB, Geremia DS, Heidemann ITSB, Colliselli L

reduzir os agravos à saúde dos trabalhadores rurais, resultando em mudanças significativas na qualidade de vida e, como consequência, aumento de produtividade. ${ }^{24}$

O demasiado esforço físico causa danos a longo prazo, pois pode provocar Lesão por Esforço Repetitivo (LER) e Distúrbios osteomusculares relacionados ao trabalho (Dort). Esses desgastes de estruturas do sistema musculoesquelético atingem não somente os trabalhadores agrícolas, mas várias categorias profissionais. ${ }^{25}$ Os entrevistados nesta pesquisa também citaram a necessidade do cuidado com os problemas musculoesqueléticos.

Problemas na coluna tem que se cuidar para não erguer peso, conforme tu vais envelhecendo, vai ficando um pouco mais difícil [...]. (Laranja)

[...] Mas eu tenho medo de desgaste de ossos, essas coisas, que a gente caminha muito durante o dia, a coluna principalmente. (Ameixa)

As doenças osteomusculares, ou musculoesqueléticas e do tecido conjuntivo, são as mais comuns entre os trabalhadores rurais. Destacam-se as inflamações das articulações e ligamentos, dores lombares crônicas, cervicalgias e problemas na coluna dorsal. ${ }^{25}$

A realização de exames laboratoriais de rotina, como maneira de prevenção e, consequentemente, promoção da saúde, também foi citada pelos participantes.

Agora eu me acho jovem, a gente não faz tanto exame, mas conforme vai passando os anos, fazer uns exames [...]. (Uva)

[...] buscar prevenir com exames, o quanto antes adiantar essa rotina de check-up para tentar minimizar, não excluir os riscos [...]. (Pêssego)

Os exames de rotina podem ser ferramentas importantes para avaliação do estado de saúde. ${ }^{6}$ As menções dessa estratégia nas falas demonstram a predominância do modelo biomédico na sociedade, pois revelam a preocupação no diagnóstico de doenças, sem levar em conta os determinantes sociais.

As questões de doenças hereditárias também foram evidenciadas nas entrevistas:

Minha maior preocupação é a questão hereditária, os irmãos do meu avô, e o meu avô todos morreram de câncer [...] meu pai faz tratamento para 
Promoção da saúde do jovem agricultor familiar: perspectiva para um envelhecimento... | 14

câncer, meu tio também fez tratamento [...] e a gente sabe que os agrotóxicos estão bem ligados ao câncer. (Pêssego)

São raros os casos de câncer que se devem exclusivamente a fatores hereditários, familiares e étnicos, apesar de o fator genético exercer um importante papel na oncogênese. ${ }^{26}$ As causas externas, representadas pelo meio ambiente e os hábitos ou costumes próprios de um ambiente social e cultural, são os principais fatores de risco para o desenvolvimento de câncer. Desse modo, o estilo de vida adotado interfere no desenvolvimento de neoplasias.

A incidência de câncer pode estar diretamente ligada ao uso de agrotóxicos. Portanto, cabe aos profissionais da saúde a inserção de debates sobre a temática nas comunidades, buscando enfrentar essa situação e produzir estratégias para reduzir ou eliminar a contaminação dos trabalhadores rurais. A percepção dos agricultores e consumidores quanto aos elevados riscos da utilização de agrotóxicos para a saúde humana e meio ambiente é essencial na mudança dessa realidade. ${ }^{27}$

Apesar dos participantes relatarem cuidados com a sua saúde, alguns dos jovens afirmam não haver preocupação com possíveis consequências no futuro.

Não parei [...]. Não tenho muita preocupação com isso, mas teria que se preocupar mais. (Maracujá)

[...] hoje você é novo, você não sente os riscos, você acha que não está correndo risco para o futuro e não para para pensar, então você vai ver que em longo prazo pode incomodar [...]. (Figo)

Há uma lacuna na literatura sobre os motivos de o jovem não se preocupar com a saúde. Uma possível explicação para essa falta de preocupação, pode estar relacionada à maior resistência física na juventude, ou por acreditar que a exposição a riscos no presente não implicará em sua saúde na fase adulta e para o envelhecimento saudável. Nessa perspectiva, fazse necessário estabelecer uma relação horizontal entre os jovens e profissionais de saúde, principalmente o enfermeiro, buscando uma nova forma de abordagem na atenção à saúde. A 
15 | Urio A, SouzaJB, Geremia DS, Heidemann ITSB, Colliselli L

incorporação da ideia do jovem como protagonista na construção do processo de saúde pessoal e coletivo conferirá um potencial de emancipação, autonomia e responsabilidade social. ${ }^{3}$

\section{Considerações finais}

A promoção da saúde é realizada pelo jovem agricultor familiar nos cuidados com a alimentação, ingesta hídrica, adaptações ao clima e manutenção das boas relações familiares. Evidenciou-se que os exercícios físicos não são praticados pelos participantes devido às atividades laborais demandarem intenso esforço físico. Diante da escassez de tempo em decorrência dos intensos afazeres, alguns dos entrevistados afirmaram que não costumam promover a própria saúde.

Alguns dos jovens demonstram preocupações com a sua saúde na terceira idade, relacionando momentos de lazer como estratégia para promover a saúde. Foram mencionadas a necessidade de inserção de novas tecnologias para aliviar o esforço físico e de realização de exames preventivos diante das doenças hereditárias e comorbidades associadas, relacionando-as às atividades realizadas no presente. Outros entrevistados não consideraram relevante a preocupação com suas condições de saúde no futuro.

Nessa perspectiva, cabe o despertar dos enfermeiros para a população rural, de modo que as políticas existentes para efetivação da promoção da saúde sejam postas em prática. Vislumbra-se a necessidade de pesquisas que versem sobre a temática aqui proposta, pois são escassos os estudos sobre a promoção da saúde do jovem agricultor familiar.

Salienta-se a inserção da educação em saúde como forma de promover a saúde na população rural. Com isso, buscar-se-ia não apenas compartilhar conhecimento, mas estabelecer vínculos entre os profissionais e os agricultores, contribuindo para a inclusão social e a sua participação ativa no autocuidado. 
Promoção da saúde do jovem agricultor familiar: perspectiva para um envelhecimento... | 16

Existem obstáculos e limites para as práticas de promoção da saúde, sendo necessário reorganiza-las para: oportunizar condições equânimes de saúde a todos os jovens agricultores; garantir seus direitos no Sistema Único de Saúde; gerar possibilidades para melhorar a qualidade de vida do agricultor no presente, na fase adulta e no envelhecimento saudável.

Apesar de o estudo ter sido realizado em um município onde a agricultura familiar é intensa, os jovens geralmente mudam-se para a zona urbana em busca de emprego com salário fixo. Assim, a dificuldade para encontrar os 10 jovens agricultores se constituiu na principal limitação deste estudo. Tal dificuldade revela outra problemática. Reconhecendo que a agricultura familiar é responsável pelos alimentos que sustentam muitos dos lares urbanos, a permanência da juventude no campo precisa ser debatida. Da mesma forma, a criação de incentivos e benefícios para esses jovens indica a necessidade de pesquisas que envolvam esse público.

\section{Referências}

1. Rocha TALCG, Oliveira FN. Segurança e saúde do trabalhador: vulnerabilidade e percepções de riscos relacionados ao uso de agroquímicos em um polo de fruticultura irrigada do Rio Grande do Norte. Gest Prod. 2016;23(3):600-11. doi: https://doi.org/10.1590/0104-530x1219-14

2. Moreira JPL, Oliveira BLCA, Muzi CD, Cunha CLF, Brito AS, Luiz RR. A saúde dos trabalhadores da atividade rural no Brasil. Cad Saúde Pública. 2014;31(8):1698-708. doi: https://doi.org/10.1590/0102$311 \times 00105114$

3. Cassal VB, Azevedo LF, Ferreira RP, Silva DG, Simão RS. Agrotóxicos: uma revisão de suas consequências para a saúde pública. REGET. 2014;18(1):437-45. doi: http://dx.doi.org/10.5902/2236117012498

4. Ministério da Saúde (BR), Secretaria de Gestão Estratégica e Participativa, Departamento de Apoio à Gestão Participativa. Política Nacional de Saúde Integral das Populações do Campo da Floresta [Internet]. Brasília (DF): Ministério da Saúde; 2013 [acesso em 2018 ago 10]. Disponível em: http://bvsms.saude.gov.br/bvs/publicacoes/politica_nacional_saude_populacoes_campo.pdf

5. Ministério da Saúde (BR), Secretaria de Vigilância em Saúde, Coordenação-Geral de Desenvolvimento 
da Epidemiologia em Serviços. Guia de Vigilância em Saúde [Internet]. Brasília (DF): Ministério da Saúde; 2017 [acesso em 2018 set 20]. Disponível em: http://bvsms.saude.gov.br/bvs/publicacoes/guia_vigilancia_saude_volume_1.pdf

6. Ministério da Saúde (BR), Secretaria de Atenção em Saúde, Departamento de Ações Programáticas Estratégicas. Diretrizes nacionais para a atenção integral à saúde de adolescentes e jovens na promoção, proteção e recuperação da saúde [Internet]. Brasília (DF): Ministério da Saúde; 2010 [acesso em 2018 out 14]. Disponível em: http://bvsms.saude.gov.br/bvs/publicacoes/diretrizes_nacionais_atencao_saude_adolescentes_jovens_pro mocao_saude.pdf

7. Carmo ME, Guizardi FL. O conceito de vulnerabilidade e seus sentidos para as políticas públicas de saúde e assistência social. Cad Saúde Pública. 2018;34(3):1-14. doi: http://dx.doi.org/10.1590/0102$311 \times 00101417$

8. Senado Federal (BR). Estatuto da juventude: atos internacionais e normas correlatas [Internet]. Brasília (DF): Senado Federal; 2013 [acesso em 2018 maio 15]. Disponível em: https://www2.senado.leg.br/bdsf/bitstream/handle/id/509232/001032616.pdf

9. Pimenta MM. Ser jovem e ser adulto: identidades, representações e trajetórias [tese]. São Paulo: Universidade de São Paulo; 2007 [acesso em 2018 fev 17]. Disponível em: http://www.teses.usp.br/teses/disponiveis/8/8132/tde-15052007-111215/en.php

10. Bardin L. Análise de conteúdo. São Paulo: Edição 70; 2011. 229 p.

11. Heidemann ITSB, Cypriano CC, Gastaldo D, Jackson S, Rocha CG, Fagundes E. Estudo comparativo de práticas de promoção da saúde na atenção primária em Florianópolis, Santa Catarina, Brasil e Toronto, Ontário, Canadá. Cad Saúde Pública. 2018;34(4):1-13. doi: https://doi.org/10.1590/0102$311 \times 00214516$

12. Mallta DC, Reis AAC, Jaime PC, Morais Neto OL, Silva MMA, Akerman M. O SUS e a Política Nacional de Promoção da Saúde: perspectiva resultados, avanços e desafios em tempo de crise. Ciênc Saúde Colet. 2018;23(6):1799-809. doi: https://doi.org/10.1590/1413-81232018236.04782018

13. Triches RM, Gerhaedt TE, Schneider S. Políticas alimentares: interações entre saúde, consumo e produção de alimentos. Interações (Campo Grande). 2014;14(1):109-200. doi: https://doi.org/10.1590/S151870122014000100011

14. Silva Filho JN, Araújo LC, Yamiha C, Araújo BCA. Necessidades da reidratação para a saúde do trabalhador: uma revisão sistemática. Rev Bras Nutr Esportiva [Internet]. 2015 [acesso em 2018 set 02];9(54):578-86. Disponível em: http://www.rbne.com.br/index.php/rbne/article/view/591

15. CEREST (Campo Grande). Riscos a Saúde do trabalhador rural [Internet]. 2017 [acesso em 2018 set 26]. Disponível em: http://www.campogrande.ms.gov.br/cerest/wp- 
Promoção da saúde do jovem agricultor familiar: perspectiva para um envelhecimento... $\mid 18$

content/uploads/sites/43/2017/05/201702201024501.pdf

16. Boechat IT, Cabral HLTB, Souza CHM. A comunicação na família caracterizada pela pseudomutualidade e pelo duplo vínculo. Transformar [Internet]. 2015 [acesso em 2019 out 03];(7):227-38. Disponível em: http://www.fsj.edu.br/transformar/index.php/transformar/article/view/42

17. Silva MR, FerrettiF, Lutinski JA. Dor lombar, flexibilidade muscular e relação com o nível de atividade física de trabalhadores rurais. Saúde Debate. 2017;2(112):183-94. doi: http://dx.doi.org/10.1590/0103-1104201711215

18. Lima DF, Luiz OC. Atividade física na promoção da saúde: uma avaliação das diretrizes. Semina Cienc Biol Saúde [Internet]. 2015 [acesso em 2018 set 03];36(2):57-66. Disponível em: http://www.uel.br/revistas/uel/index.php/seminabio/article/view/22531

19. Silva JV, Domingues EAR. Adaptação cultural e validação da escala para avaliar as capacidades de autocuidado. Arch Health Sci (Online). 2017;24(4):30-6. doi: https://doi.org/10.17696/23183691.24.4.2017.686

20. Menezes MA, Stropasolas AM, Bartellos SB, organizadores. Juventude rural e políticas públicas no Brasil. Brasília (DF): Presidência da República; 2014. 268 p.

21. Senna SRCM, Dessen MA. Reflexões sobre a saúde do adolescente brasileiro. Psicol Saúde Doenças. 2015;16(2):217-29. doi: http://dx.doi.org/10.15309/15psd160208

22. Pessoa YSRQ, Aalchieri JC. Qualidade de vida em agricultores orgânicos familiares no interior paraibano. Psicol Ciênc Prof. 2014;34(2):330-43. doi: https://doi.org/10.1590/1982-3703001095012

23. Saúde em Movimento. Associação Mundial de Recreação e Lazer (World Leisure and Recreation Association - WLRA). Carta internacional de educação para o lazer [Internet]. 2003 [acesso em 2018 out $18]$.

Disponível

em:

http://www.saudeemmovimento.com.br/conteudos/conteudo_frame.asp?cod_noticia=195

24. Cunha JM, Merino GSAD, Merino EAD. Avaliação ergonômica da extração manual de raízes de mandioca em propriedades agrícolas familiares a partir do rastreamento de movimentos 3D (X-SENS). Estudos Design. 2015;23(3):60-72. doi: http://dx.doi.org/10.5151/15ergodesign-26-E032

25. Ministério da Saúde (BR), Secretaria de Vigilância em Saúde, Departamento de Vigilância em Saúde Ambiental e Saúde do Trabalhador. Dor relacionada ao trabalho: lesões por esforços repetitivos (LER): distúrbios osteomusculares relacionados ao trabalho (Dort) [Internet]. Brasília (DF): Ministério da Saúde; 2012 [acesso em 2018 set 20]. Disponível em: http://bvsms.saude.gov.br/bvs/publicacoes/dor_relacionada_trabalho_ler_dort.pdf

26. Instituto Nacional de Câncer (INCA). O que é câncer? [Internet]. 2018 [acesso em 2018 out 18]. Disponível em: http://www1.inca.gov.br/conteudo_view.asp?id=322 
19 | Urio A, SouzaJB, Geremia DS, Heidemann ITSB, Colliselli L

27. Vieiro CM, Camponogara S, Cesar-Vaz MR, Costa VZ, Beck CLC. Sociedade de risco: o uso dos agrotóxicos e implicações na saúde do trabalhador rural. Esc Anna Nery Rev Enferm. 2016;20(1):99-105. doi: https://doi.org/10.5935/1414-8145.20160014

\section{Autor correspondente}

Ângela Urio

E-mail: ange.urio@hotmail.com

Endereço: Rua Trinta, n 190, apto 02. Bairro: Altos do Indaiá. Dourados, MS, Brasil.

CEP: 79823-560.

\section{Contribuições de Autoria}

\section{1 - Ângela Urio}

Concepção e planejamento do projeto de pesquisa, análise e interpretação dos dados e redação.

2 - Jeane Barros de Souza

Concepção e planejamento do projeto de pesquisa, análise e interpretação dos dados, redação e revisão crítica.

\section{3 - Daniela Savi Geremia}

Redação e revisão crítica.

\section{4 - Ivonete Teresinha S. Buss Heidemann}

Redação e revisão crítica

\section{Autor 5 - Liane Colliselli}

Redação e revisão crítica

\section{Como citar este artigo}

Urio A, SouzaJB, Geremia DS, Heidemann ITSB, Colliselli L. Promoção da saúde do jovem agricultor familiar: perspectiva para um envelhecimento saudável. Rev. Enferm. UFSM. 2020 [Acesso em: Anos Mês Dia]; vol.10 e43: 119. DOI:https://doi.org/10.5902/2179769240131 